\title{
A PERFILAGEM SÔNICA NA DETERMINAÇÃO DE MÓDULOS DE ELASTICIDADE DINÂMICOS EM ROCHAS
}

Rubens Paschoal Cordeiro, Instituto de Pesquisas Tecnológicas do Estado de São Paulo

Vicente Luiz Galli, Instituto de Pesquisas Tecnológicas do Estado de São Paulo

Copyright 2004, SBGf - Sociedade Brasileira de Geofísica

Este texto foi preparado para a apresentação no I Simpósio de Geofísica da Sociedade Brasileira de Geofísica, São Paulo, 26-28 de setembro de 2004. Seu conteúdo foi revisado pela Comissão Tecno-científica do I SR-SBGf mas não necessariamente representa a opinião da SBGf ou de seus associados. E proibida a reprodução total ou parcial deste material para propósitos comerciais sem prévia autorização da SBGt.

\section{Resumo}

Discute-se neste trabalho a utilização da perfilagem sônica na determinação de velocidades de propagação de ondas de compressão e de cisalhamento para cálculo de módulos de elasticidade dinâmicos. O poço utilizado foi perfurado em rochas gnáissicas e para as profundidades apresentadas neste trabalho os valores de velocidade para a onda de compressão situam-se entre $4659 \mathrm{~m} / \mathrm{s}$ e $6029 \mathrm{~m} / \mathrm{s}$ e para as de cisalhamento entre $2847 \mathrm{~m} / \mathrm{s}$ e $3761 \mathrm{~m} / \mathrm{s}$. Esses resultados são parciais e estão inseridos num programa conduzido pelo Instituto para integração de parâmetros obtidos com diferentes sondas.

\section{Introdução}

Valores de velocidade de propagação de ondas sísmicas guardam relações estreitas com litologia e algumas propriedades de maciços, exemplificadas pelo grau de fraturamento e alteração, porosidade e saturação, aspectos que justificam sua utilização na avaliação de propriedades mecânicas.

Em geologia de engenharia a determinação in situ de valores de velocidade de ondas sísmicas de compressão (P) e cisalhamento (S), particularmente para cálculo de módulos de elasticidade, é feita tradicionalmente com o ensaio sísmico entre furos crosshole. Nesse ensaio, fontes de energia adequadas à geração de cada um desses tipos de ondas e receptores de freqüência apropriada e orientados para responder preferencialmente às componentes de interesse do movimento do meio, se deslocam em furos distintos, e as medições são realizadas em profundidades específicas (Dourado, 1984; Prado, 1994; Prado et al., 2000).

A perfilagem sônica, discutida neste trabalho, se constitui também numa ferramenta para determinação de velocidades, particularmente em maciços rochosos (Schlumberger, 1985). É utilizada de forma rotineira na exploração petrolífera mas seu uso em geologia de engenharia ainda é restrito. O sistema de medidas, constituído por dois transmissores e dois receptores, se desloca de forma contínua ao longo de um único furo, e as medições são executadas de modo automático em intervalos fixos de deslocamento. De forma diferente do ensaio crosshole, em que os registros para análise das ondas $\mathrm{P}$ e $\mathrm{S}$ são distintos, na perfilagem sônica os dois tipos de ondas devem ser identificados no mesmo registro.

\section{SOBRE AS VELOCIDADES SÍSMICAS E OS MÓDULOS DE ELASTICIDADE}

Durante a passagem de uma onda, o movimento do meio registrado num receptor é bastante complexo. Diferentes tipos de ondas elásticas, geradas simultaneamente na liberação de energia pelo transmissor, ou resultantes da conversão de um tipo de onda em outro nas interfaces entre meios com diferentes propriedades acústicas, e que se propagam com valores distintos de velocidade, se superpõem nos sismogramas.

Em geologia de engenharia o interesse maior é pelas ondas de compressão (P) e cisalhamento (S), cujas velocidades, além de individualmente fornecerem informações sobre a qualidade do maciço, são utilizadas no cálculo de módulos de elasticidade.

As ondas $P$ são mais rápidas, apresentam freqüência mais elevada e se constituem no primeiro pulso de grande energia identificado no sismograma. As ondas $\mathrm{S}$ apresentam velocidade mais baixa, menor conteúdo em freqüência, porém maior amplitude, critério que favorece a sua identificação em meio às fases posteriores da onda de compressão.

Em relação ao movimento das partículas do meio, na passagem da onda $P$ elas se deslocam na direção de propagação da onda e para a onda $S$ o movimento é perpendicular. Assim, o esforço associado à onda $P$ é resultante de uma compressão uniaxial enquanto na onda S o meio está sujeito a um esforço de cisalhamento.

As velocidades das ondas $P$ e $S$, representadas, respectivamente, por $V_{p} e V_{s}$ estão relacionadas às constantes elásticas e densidade por meio das equações:

$$
\begin{aligned}
& V_{p}=\sqrt{\left(\left(K+\frac{4}{3} G\right) / \rho\right)} \\
& V_{s}=\sqrt{\frac{G}{\rho}}
\end{aligned}
$$


onde $K$ é o módulo de bulk (ou incompressibilidade), $G$ o módulo de cisalhamento e $\rho$ a densidade.

Para a maioria das rochas a onda $S$ apresenta velocidade um pouco maior que a metade da velocidade da onda $P$ e não se propaga nos fluidos, para os quais 0 módulo de cisalhamento é igual a zero.

$\mathrm{V}_{\mathrm{p}}$ e $\mathrm{V}_{\mathrm{s}}$ são dependentes das relações $\frac{K}{\rho}$ e $\frac{G}{\rho}$ e, normalmente, crescem na mesma direção. Redução da porosidade em materiais rochosos, por exemplo, provoca aumento na densidade, mas os incrementos nos módulos são mais acentuados, resultando em velocidades mais elevadas.

Em rochas de baixa porosidade, e nessa classificação estão incluídas as ígneas e metamórficas, as velocidades são controladas por sua composição e, em princípio, preditas pelo conhecimento das velocidades dos bens minerais. A presença de fraturas abertas, no entanto, comuns na escala de profundidade em que a geologia de engenharia atua, pode reduzir substancialmente seus valores.

Em rochas de média a alta porosidade a velocidade da onda $\mathrm{P}$ depende também do fluido presente. Para porosidades entre 20 e 40 por cento, $V_{p}$ pode ser predita pela equação seguinte (Griffiths \& King, 1983):

$\frac{1}{V_{p}}=\frac{\phi}{V_{f}}+\frac{1-\phi}{V_{m}}$

onde $\phi$ corresponde à porosidade e $V_{p}, V_{f}, V_{m}$ indicam, respectivamente, as velocidades da onda $\mathrm{P}$, do fluido e da matriz.

As equações 1 e 2 podem ser reescritas, resultando nas expressões seguintes para as constantes elásticas:

Módulo de Bulk (Gpa) $\quad K=\rho\left(V_{p}^{2}-\frac{4}{3} V_{s}^{2}\right)$

Módulo de cisalhamento (Gpa) $G=\rho V_{s}^{2}$

Módulo de Young (Gpa) $E=\rho V_{s} 2 \frac{\left(3 V_{p}{ }^{2}-4 V_{s}{ }^{2}\right)}{\left(V_{p}{ }^{2}-V_{s}{ }^{2}\right)}$
Razão de Poisson (adimensional) $v=\frac{\left(V_{p}^{2}-2 V_{s}^{2}\right)}{\left(2\left(V_{p}^{2}-V_{s}^{2}\right)\right)}$

onde $\rho$ é a densidade em $\mathrm{Mg} / \mathrm{m}^{3}$.

\section{SOBRE O SISTEMA DE PERFILAGEM SÔNICA CONTINNUA}

O sistema de perfilagem sônica contínua fabricado pela empresa inglesa Robertson Geologging Ltd., ilustrado na Figura 1, é constituído por dois transmissores piezoelétricos (Ts e Ti) e dois receptores (Rs e $\mathrm{Ri}$ ). Apresenta comprimento de 4,35 m, diâmetro de 0,060 m e durante o seu deslocamento é mantido no centro do furo com o auxílio de centralizadores. Opera em furos abertos e revestidos, sempre preenchidos por um fluido.

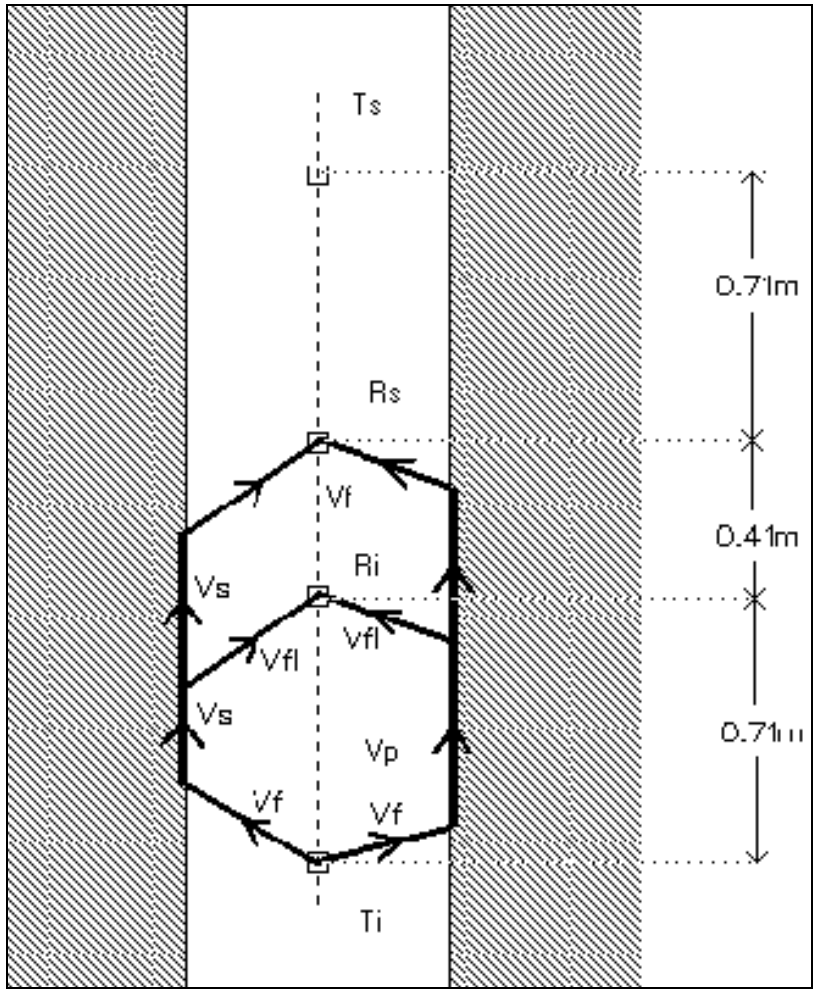

Figura 1. Sistema centrado em furo preenchido por fluido. Para o transmissor inferior (Ti) a trajetória de tempo mínimo para a onda $\mathrm{P}$ é mostrada à direita, e para a onda $S$, à esquerda. $\mathrm{Vp}$ e $\mathrm{Vs}$ indicam, respectivamente, as velocidades das ondas $P$ e $S$ no maciço, e Vf a velocidade do fluido.

Os dois transmissores liberam energia de forma alternada que se transmite pelo fluido como onda longitudinal. Ao atingir de forma oblíqua a parede do furo, se converte em ondas P e S (tipo Sv), que se propagam pelo maciço, retornando na forma de onda $P$ para serem captadas nos receptores, obedecendo sempre a lei de Snell generalizada. 
O próprio sistema faz as leituras dos valores de tempo para as primeiras chegadas de energia em cada receptor (ondas P), a cada $0,01 \mathrm{~m}$ de deslocamento, e calcula a vagarosidade (inverso da velocidade) com o uso da equação 8.

vagarosidade $=\frac{\Delta T_{1}+\Delta T_{2}}{2 \text { vezes a distância entre receptores }}$

onde,

$\Delta T_{1}=$ diferença entre os valores de tempo lidos pelo sistema nos dois receptores, quando a energia é liberada no transmissor superior.

$\Delta T_{2}=$ diferença entre os valores de tempo lidos pelo sistema nos dois receptores quando a energia é liberada no transmissor inferior.

A cada $0,20 \mathrm{~m}$ de deslocamento o sistema armazena formas de onda completas (energia liberada no transmissor inferior), captadas em ambos receptores, com razão de amostragem de $4 \mu \mathrm{s}$ e comprimento total do registro de $1920 \mu \mathrm{sec}$. Esses registros são processados para identificação criteriosa das ondas sísmicas de compressão e cisalhamento e determinação dos valores de velocidade de propagação das ondas $\mathrm{P}$ e $\mathrm{S}$, que se constituem nos parâmetros de entrada para cálculo dos módulos de elasticidade dinâmicos.

\section{PROCESSAMENTO DOS DADOS}

O passo inicial no processamento básico consiste em definir sobre os registros obtidos em uma profundidade específica (receptores próximo e distante) as janelas de tempo associadas ao campo principal de ocorrência das ondas $\mathrm{P}$ e $\mathrm{S}$, fazendo uso da transformada rápida de Fourier. Para a onda $P$ espera-se que a freqüência dominante esteja ao redor de $23 \mathrm{kHz}$, que é a freqüência nominal do transmissor (Figura 2).

O passo seguinte consiste em definir sobre os dois registros os tempos das primeiras chegadas (ou suas fases) para as ondas $\mathrm{P}$ e S. A diferença entre os valores de tempo observados possibilita o cálculo da vagarosidade. As amplitudes para as ondas $\mathrm{P}$ são muito baixas e, em conseqüência, para facilitar a sua análise a mais alta amplitude observada no registro é truncada em 20 por cento (Figura 3 ).

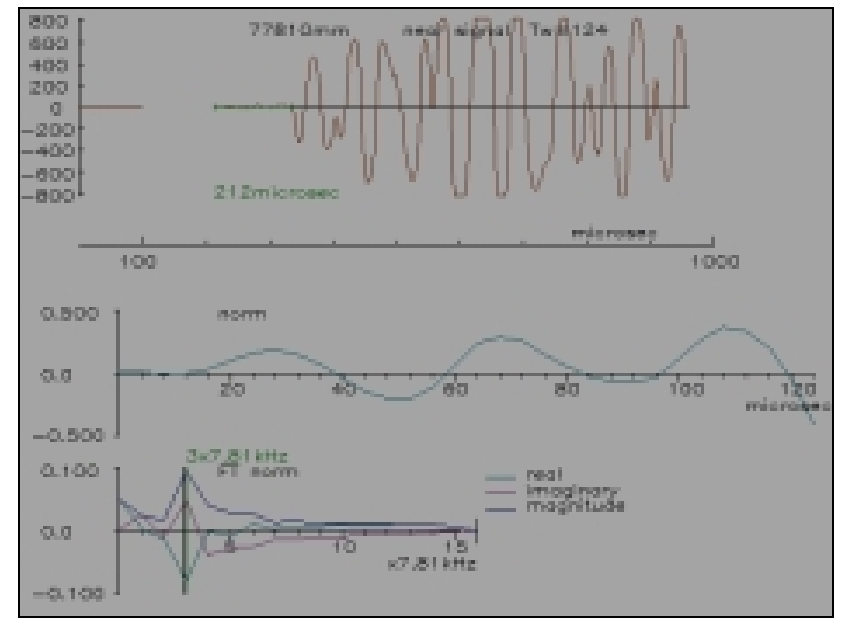

Figura 2. Superior: observa-se a janela de $124 \mu$ s que se inicia em $212 \mu$ s e que caracteriza o campo principal da onda P. Intermediária: amplitude normalizada para o intervalo correspondente à janela. Inferior: vetor magnitude da função densidade espectral mostrando a freqüência dominante em $23,44 \mathrm{kHz}$.

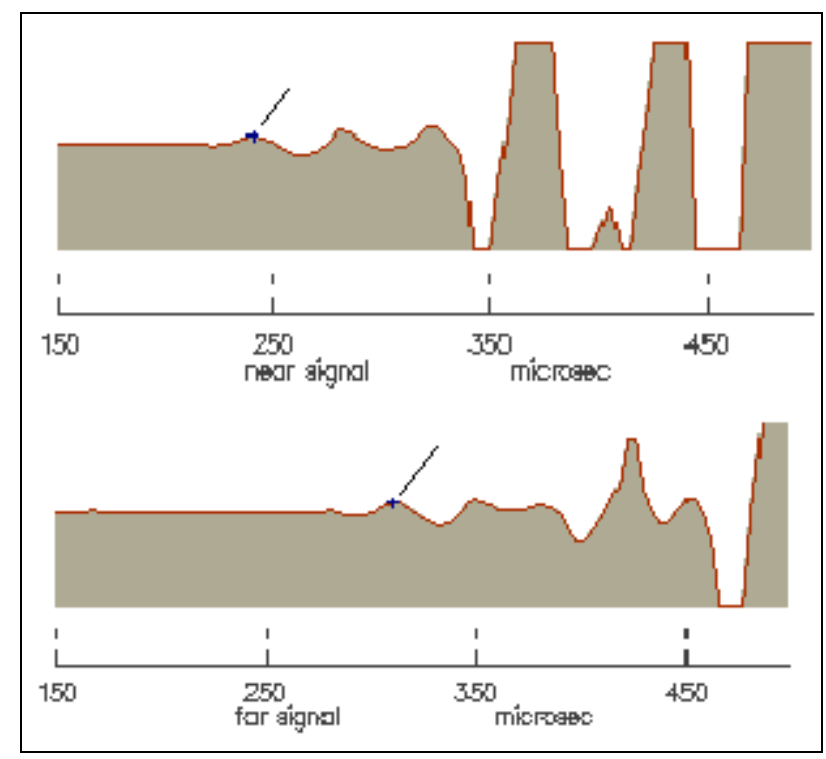

Figura 3. Fases da onda $P$ para os receptores próximo (superior) e distante. A diferença entre os valores de tempo possibilita o cálculo da vagarosidade. Observar que as amplitudes maiores correspondentes às ondas $S$ e às ondas que se propagam pelo fluido são truncadas, ressaltando as amplitudes da onda $P$. 


\section{RESULTADOS E CONSIDERAÇÕES FINAIS}

$\mathrm{Na}$ Figura 4 são apresentados resultados parciais de ensaios executados em poço perfurado em área de ocorrência de rochas gnáissicas e localizado nas instalações do Hospital Universitário da Universidade de São Paulo, na cidade de São Paulo. Esses ensaios estão inseridos num programa do Instituto para integração de parâmetros obtidos com diferentes sondas.

Para o intervalo apresentado a distribuição dos valores de velocidade das ondas $P$ e $S$ indicam maciço pouco fraturado. Ausência de onda $S$, que poderia indicar a presença de fraturas abertas, não ocorre nesse intervalo, mas há indicação de que o fenômeno esteja ocorrendo em outros intervalos, particularmente em profundidades menores.

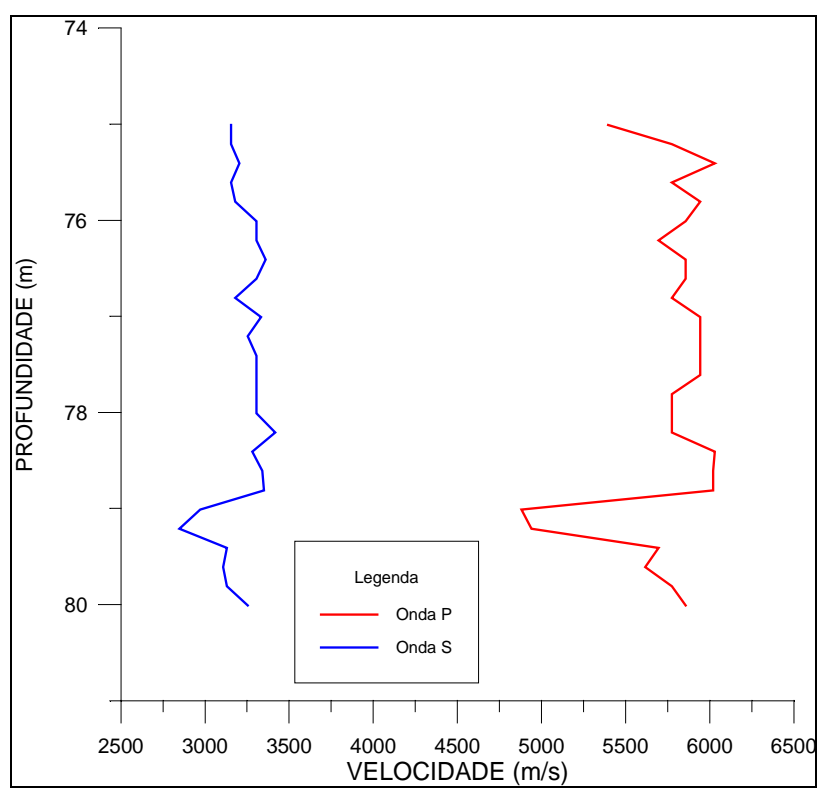

Figura 4. Valores de velocidade para as ondas $\mathrm{P}$ e S.

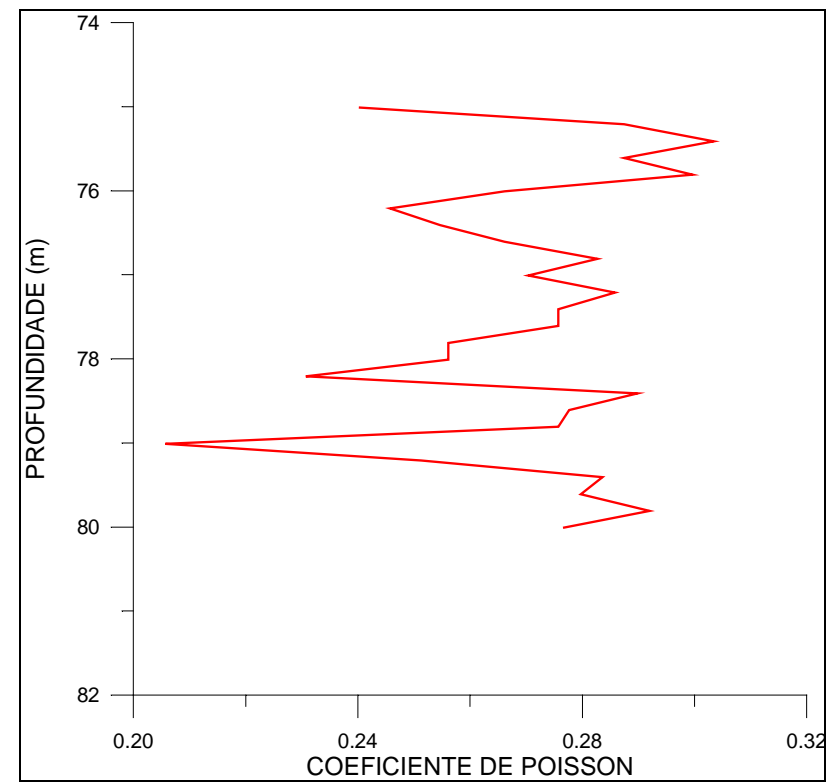

Figura 5. Valores do coeficiente de Poisson

\section{Referências}

Dourado, J.C. A utlização da sísmica na determinação de parâmetros elásticos de maciços rochosos e terrosos in situ. São Paulo, 1984: ABGE. 12 p. (Publicação especial).

Griffiths, D.H.; King, R.F. Applied Geophysics for Geologists \& Engineers. New York, Pergamon Press Inc, 1983.

Prado, R. L. O ensaio sísmico entre furos (crosshole) no estudo de maciços terrosos e rochosos. São Paulo, 1994. 123 p. Dissertação de Mestrado - Instituto Astronômico e Geofísico da Universidade de São Paulo.

Prado, R. L.; Shukowsky, W. O Emprego do Método Sísmico Crosshole na Cidade de São Paulo: Discussão de Procedimentos de Ensaio e Resultados. Solos e Rochas - Revista Latino-americana de Geotecnia, v.23, n.2, p.79-91, 2000.

Santamarina, J.C.; Klein, K. A.; Fam, M.A. Soils and Waves. Particulate Materials Behavior, Characterization and Process Monitoring. New York, John Wiley \& Sons, Ltd, 2001.

Schlumberger. Avaliação de Formações no Brasil. Publicação interna, 1985. 